\title{
CUSTO TRIBUTÁRIO DE EMPRESAS LISTADAS NA BM\&FBOVESPA
}

\author{
Tax cost of listed companies in bm\&fbovespa \\ Costo fiscal de las compañias cotizadas em bm\&fbovespa
}

JEFFERSON
PEREIRA
ANDRADE
Graduando em
Ciências
Contábeis pela
UFPB
PAULINA
MORENO LÚCIO
SOUZA
Graduanda em
Ciências
Contábeis UFPB
WENNER
GLAUCIO LOPES
LUCENA
Professor do
Programa
Multiinstitucional
e Inter-regional
de Pós-Graduação
em Ciências
Contábeis
UnB/UFPB/UFRN

Submetido em 01.10.2015. Aprovado em 26.07.2016 Avaliado pelo processo de double blind review.

\section{RESUMO}

Os tributos são responsáveis pela manutenção do Estado que converte esses tributos em bens e serviços para a população, por outro lado esses tributos geram custos as empresas onerando os meios de produções e consequentemente encarecendo os produtos e serviços que chegam até o consumidor final. O presente trabalho tem por objetivo determinar o custo tributário de empresas de seis setores de atuação da BM\&FBovespa e verificar se existem diferenças na carga tributária de empresas com maior e menor valor adicionado caracterizando o estudo como descritivo, bibliográfico e documental com abordagem quantitativa. Chegou-se à conclusão que no período de tempo referente aos anos de 2009 até 2014 o setor de consumo cíclico e consumo não cíclico foi o que em média arcou com o maior custo tributário superando a o valor de $\mathrm{R} \$ 1.000 .000$, além disso, foi possível perceber diferenças nas cargas tributárias suportadas pelas empresas de menor e maior valor adicionado corroborando assim com o estudo de Konraht, Schãfer e Ferreira (2014).

Palavras-chave: Custo de tributação; Valor adicionado e Setores econômicos.

\section{ABSTRACT}

Taxes are responsible for maintaining the rule that converts these taxes on goods and services for the population, on the other hand these taxes generate costs burdening businesses the means of production and consequently endearing products and services that they reap by the end consumer. This study aims to determine the tax cost of six areas of activity companies in the BM\&FBovespa and check for differences in the tax burden of companies with the highest and lowest value added characterizing the study as descriptive, bibliographic and documentary with a quantitative approach. We reached the conclusion that the time period for the years 2009 to 2014 the cyclical consumer sector and consumer staples was which on average has borne the largest tax costs exceeding the amount of $\mathrm{R} \$ 1,000,000$, in addition, it was revealed differences in tax burdens borne by companies with lower and higher value added thus corroborating the study Konraht, Schafer and Ferreira (2014).

Keywords: tax costs, added value, Company sectors.

\section{RESUMEN}

Los impuestos son responsables de mantener la regla que convierte estos impuestos sobre bienes y servicios para la población, por el contrario estos impuestos generan costos que pesan sobre las compañias de los medios de producción y los productos y servicios, en consecuencia entrañables que cosechan por el consumidor final. Este estudio tiene como objetivo determinar el costo fiscal de las seis áreas de compañias de actividades en la BM\&FBovespa y compruebe si hay diferencias en la carga fiscal de las compañias con el valor más alto y el más bajo añadido que caracteriza el estudio como descriptiva, bibliográfica y documental con un enfoque cuantitativo. Llegamos a la conclusión de que el período de tiempo para los años 2009 a 2014 el sector de consumo cíclico y bienes de consumo básico fue que en promedio ha dado los mayores costos fiscales que superen el monto de $\mathrm{R} \$ 1.000 .000$, además, se reveló diferencias en las cargas fiscales a cargo de las compañias con un valor más bajo y más alto añadió tanto corroborando el estudio Konraht, Schafer y Ferreira (2014).

Palabras clave: costos de impuestos, valor añadido, sectores de la industria. 


\section{INTRODUÇÃO}

Todo Estado organizado necessita de recursos financeiros para subsidiar as suas atividades em prol da coletividade, esses recursos, em sua maioria decorrem da soberania do Estado instituindo a tributação.

O dinheiro arrecadado por meio da tributação permite ao Estado atender as necessidades básicas do país, além disso, custeiam atividades que não são próprias do Estado e que ele desenvolve a partir de suas autarquias. Em contrapartida a arrecadação de tributos pode afetar significativamente a economia privada, incentivando setores de atividades; ramos econômicos e regiões ou ainda desestimulando o consumo de certos bens (GALLO, 2007).

Segundo Machado, Azevedo e Silva (2014) no Brasil a tributação inclui contribuições sociais, impostos, taxas, bem como contribuições parafiscais. Todos os tributos possuem uma regulamentação própria que segue as diretrizes do Código Tributário Nacional, cada um deles está atrelado a um fato gerado e a uma alíquota própria. Tanto pessoas físicas como pessoas jurídicas estão sujeitas a tributação, sendo que dentre essas últimas estão às empresas.

No ambiente corporativo os tributos representam custos que são imputados aos produtos e serviços e consequentemente repassados ao consumidor final por meio da elevação de preços. Segundo a European Commission (2013) além dos tributos propriamente ditos, as empresas também arcam com uma série de outros custos para manter sua regularização com a legislação fiscal do país, referentes a arquivamento, emissão de guias, software entre outros necessários para que a arrecadação ocorra, esses custos recebem o nome de Compliance Costs of Taxation ou em português Custo de Conformidade.

Em um mercado de grande concorrência as empresas são forçadas a desenvolverem capacidades diferenciadoras que iram proporcionar que se tornem mais competitivas, uma dessas maneiras é a redução de custos (MARTINS e DANTAS, 2010). Dessa forma insere-se a importância de se conhecer os custos tributários e desenvolver programas capazes de aperfeiçoar esses custos reduzindo ao mínimo por meio do planejamento tributário.

No Brasil os custos tributários estão entre os maiores do mundo, segundo informações divulgadas pela Receita Federal do Brasil os tributos pagos dentro do território nacional somaram o equivalente a 35,95\% do Produto Interno Bruto (PIB) do país em 2013.

Partindo deste contexto, surge a seguinte questão de pesquisa: Qual o custo tributário médio referente ao período de 2009 a 2014 das empresas que negociam ações na BM\&FBOVESPA?

O presente trabalho tem por objetivo determinar o custo tributário médio das companhias de capital aberto de seis setores de atividade que negociam ações na Bolsa de Valores, Mercado e Futuro de São Paulo, além de comparar se existem diferenças estatísticas entre as empresas com maior e menor valor agregado com relação as suas cargas tributárias.

A pesquisa se justifica por poder contribuir para o debate das políticas fiscais do país, principalmente no momento vivido atualmente onde o processo eleitoral de Outubro de 2014 provocou mudanças na equipe econômica do país e um debate acerca de uma reforma tributária. 


\section{REFERENCIAL TEORICO}

\subsection{Tributos}

Os tributos são definidos de acordo com o artigo terceiro do Código Tributário Nacional como "[...] toda prestação pecuniária compulsória, em moeda ou cujo valor nela se possa exprimir, que não constitua sanção de ato ilícito, instituída em lei e cobrada mediante atividade administrativa plenamente vinculada" (Brasil, 1966). Em outras palavras os tributos não resultam de punições ou qualquer outro tipo de penalização e sempre é cobrado em moeda, constitui um agregado maior que engloba diferentes espécies tributárias. As espécies tributárias por sua vez apresentam-se na forma de impostos; taxas e contribuições de melhoria.

Os impostos são tributos cuja obrigação tem por fato gerador uma situação independente de qualquer atividade estatal especifica com relação ao contribuinte (BRASIL, 1966). Esta é a espécie tributária mais conhecida e frequentemente são encaradas como sinônimos de tributos o que não é verdade.

As taxas de acordo com Curcino, Ávila e Malaquias (2012) tem por objetivo custearem os serviços públicos fundamentais prestados diretamente pelo Estado. Não é permitido que o mesmo fato gerador que deu origem a um imposto seja o mesmo que deu origem a uma taxa. São exemplos de tributos que se enquadram nessa categoria as taxas de iluminação que integra a conta de energia elétrica e a de coleta de resíduos cobrada pelas prefeituras.

A Contribuição de Melhoria é o tributo criado com o objetivo de recuperar por parte do estado os custos de obras públicas que tenham provocados ganhos a pessoas físicas ou jurídicas por meio da valorização imobiliária (PINHO e NASCIMENTO, 2006). Será devido ao Estado a contribuição de melhoria sempre que um imóvel sofre acréscimo em seu valor devido qualquer obra pública.

Os tributos brasileiros ainda podem se apresentar na forma de Contribuições Sociais e Empréstimos compulsórios.

As contribuições sociais são de responsabilidade exclusiva da união e apresenta uma subclassificação de acordo com o artigo 149 da CF podendo ser de três tipos: contribuição de intervenção no domínio público (CIDE), contribuições de interesse da categoria e as contribuições sociais propriamente ditas. A distinção entre o que é contribuição social e o que é imposto reside no fato que o imposto atende aos gastos do Estado e a contribuição tem por finalidade atender determinadas demandas.

Os Empréstimos Compulsórios também são de atribuição exclusiva da União e só podem ser instituídos em caso de guerra ou ameaça; calamidade pública onde os recursos orçamentários disponíveis não sejam suficientes e em casos onde a conjuntura exija do estado poder aquisitivo (BRASIL, 1966). Ainda sobre os empréstimos compulsórios muito se tem questionado sua adequação ao conceito de tributos devido ao fato de que irá existir o ressarcimento do valor pago pelo contribuindo em um futuro não previsível.

\subsection{Custo dos Tributos para as Empresas Brasileiras}

Conforme seu faturamento anual as empresas podem ser classificadas quanto ao seu porte (pequenas; médias ou grandes) e assim desfrutar da possibilidade oferecida pela legislação como a escolha da forma de tributação, podendo essa ser o Simples nacional; 
Lucro real ou Lucro presumido. Mesmo assim a tributação do país ainda é muito elevada e segundo Siqueira et al.(2012) os impostos indiretos formam um conjunto extremamente complexo que utilizam diferentes alíquotas e incidem em grande proporção sobre os insumos utilizados na produção de bens e serviços, como consequência os consumidores finais pagam muito mais por esses produtos e serviços e desconhecem a taxa efetiva de impostos neles alocados.

A complexa legislação e as suas frequentes alterações exigem das empresas atenção especial, dando espaço ao chamado planejamento tributário que visa justamente à redução desses custos por meio de artifícios legais provenientes da própria legislação fiscal. A falta de conhecimento da legislação pode implicar em custos desnecessários ou a erros de cálculos que podem ocasionar punições por parte das entidades arrecadadoras. Para Ferreira, Lorandi e Poluceno (2011) se antes o aprendizado era construído junto a prática hoje não é mais possível, o ambiente empresarial atual exige estudo e planejamento.

Um dos grandes problemas enfrentados pelas empresas brasileiras antes da reforma tributária ocorrida em 2003 (comentada mais adiante) era o chamado efeito cascata que ocorria no Programa de Integração Social (PIS); a Contribuição para o Financiamento da Seguridade Social (Cofins); a Contribuição Provisória sobre Movimentação Financeira (CPMF); Imposto de Renda das Pessoas Jurídicas (IRPJ) e a Contribuição Social sobre o Lucro Líquido (CSLL) quando cobrados sobre o lucro presumido; o Sistema Integrado de Pagamento de Impostos e Contribuições das Microempresas e Empresas de Pequeno Porte (Simples), além do Imposto sobre Serviços (ISS) e Imposto sobre Produtos Industrializados (IPI) SILVA, TOURINHO e ALVES (2004). A Cumulatividade desses impostos tornava mais caro os sistemas produtivos e as empresas refletiam esses custos nos preços dos produtos e serviços colocados no mercado, com a reforma tributária de 2003 esse problema foi amenizado.

Konraht, Schãfer e Ferreira (2014) afirmam que a carga tributária está diretamente relacionada às empresas uma vez que elas representam custos para as mesmas, esses custos oneram o sistema produtivo por meio da sua incidência nos fatores de produção.

Segundo a Receita Federal do Brasil (2014) a alguns anos tem se percebido um aumento constante na carga tributária anual, crescendo de 33,30\% em 2009 para 35,95\% em 2013. Para Pohlmam e ludicibus (2010) apenas o imposto de renda e a contribuição social apontam uma alíquota em torno de $34 \%$ do lucro tributável.

\subsection{Valor Adicionado e Tributação}

O valor adicionado é a riqueza acumulada pela empresa, medida pela diferença entre a receita de vendas e os produtos adquiridos de terceiros, é evidenciado por meio da Demonstração do Valor Adicionado (DVA). A DVA tem por característica, sua fundamentação em conceitos macroeconômicos onde apresenta a parte de contribuição que a entidade tem na formação do PIB, sendo eliminados valores que possam influenciar na dupla-contagem (CPC 09).

Desde a publicação da lei 11.638/07 que alterou a lei 6.404/76 tornou-se obrigatória sua publicação por parte das empresas de capital aberto. Segundo Machado, Macedo e Machado (2015) entre os objetivos da Demonstração do Valor Adicionado além da evidenciação da riqueza gerada ela demonstra a distribuição desse valor em relação aos funcionários, governo e os detentores de capital. 
Nos últimos anos tem surgidos debates acerca da utilização desse valor como base de cálculo para a tributação. Um relatório publicado pela Organização para a Cooperação e Desenvolvimento Econômico (OCDE) incentiva debates graduais acerca da substituição da cobrança de tributos, para ela esses debates devem gerar no mínimo uma conversão das contribuições referentes aos empregadores por um imposto cobrado em cima do valor adicionado das empresas, assim os impostos indiretos ficariam mais eficientes.

Nos últimos anos tem se notado que a maioria dos países tem buscado realizar grandes reformas tributárias que contemplem a necessidade de redução da carga tributária em cima das empresas contribuintes (CALDEIRA, 2006).

Silva, Tourinho e Alves (2004) informam que no ano de 2003, o Congresso Nacional Brasileiro apresentou o projeto de emenda constitucional (PEC) n-41-A que propunha uma reforma no sistema tributário visando à resolução de três problemas principais enfrentados naquele momento: cumulatividade de impostos e contribuições; guerra fiscal e a extrema complexidade do sistema. Entre as propostas dessa reforma uma delas é a substituição da base de cálculo da Contribuição Para o Financiamento da Seguridade Social (Cofins) pelo valor agregado produzido pela empresa. Mas apenas parte da proposta foi aprovada ficando de fora a mudança de base de cálculo da Cofins.

Atualmente a proposta mais recente referente a reforma tributária enviada ao congresso nacional é de 2008 e foca impostos incidentes sobre os bens e serviços e baseando-se na unificação de três impostos federais em um único incidente sobre o valor adicionado e uniformização da legislação do ICMS ( Siqueira et al., 2012).

\section{METODOLOGIA}

\subsection{Tipologia de Pesquisa}

A presente pesquisa baseia-se no trabalho de Konraht, Schãfer e Ferreira (2014) e caracteriza quanto aos objetivos como descritiva que segundo Michel (2009) trata-se em geral do levantamento de características sobre uma população, um fenômeno ou fato ou estabelecimento de relação entre variáveis controladas.

Quanto aos procedimentos, a pesquisa se enquadra como bibliográfica, sendo "desenvolvida a partir de material já elaborado, constituiu principalmente de livros e artigo. [...]", (Gil, 2012, p. 50); e documental que se assemelha à pesquisa bibliográfica sendo que a única diferença entre ambas está na natureza das fontes, enquanto uma se utiliza da contribuição de vários autores a outra se vale de materiais ou documentos que ainda não foram analisados ou que podem ser reelaborados, GIL (2012).

Quanto à abordagem, a pesquisa classifica-se como quantitativa que como o próprio nome sugere, caracteriza-se pelo emprego de quantificação seja por meio de coleta das informações como no tratamento dessas através da análise estatística da mais simples como a estatística descritiva a mais complexa análise de regressão (RICHARDSON, 1985).

\subsection{Universo e amostra}

O universo pesquisado compreende as companhias de capital aberto que negociam ações na Bolsa de Valores de São Paulo (BM\&FBOVESPA) na data de 20 de junho de 2015, que nesta data totalizavam 359 empresas classificadas em dez setores diferentes, conforme classificação da própria bolsa. 
A amostra pesquisada é composta de 131 empresas de seis setores diferentes escolhidas conforme a disponibilidade de dados, chegando à seguinte amostra.

\begin{tabular}{|l|c|}
\hline $\begin{array}{c}\text { Setor de Atuação conforme } \\
\text { Bovespa }\end{array}$ & $\begin{array}{c}\text { No de } \\
\text { empresas da } \\
\text { amostra }\end{array}$ \\
\hline Bens Industriais (BI) & 18 \\
\hline Construção e Transporte (CT) & 31 \\
\hline Financeiro e outros (FO) & 14 \\
\hline Materiais Básicos (MB) & 21 \\
\hline Consumo Cíclico (CC) & 24 \\
\hline Consumo não Cíclico (CNC) & 23 \\
\hline Total & 131 \\
\hline
\end{tabular}

Quadro 01- Composição da amostra.

Fonte: Elaborado pelos autores (2015).

As empresas que possuíam dados faltosos foram eliminadas da amostra tornando os dados uniformes para todos os anos analisados.

\subsection{Procedimentos Metodológicos}

Os dados utilizados na pesquisa foram extraídos das demonstrações contábeis coletadas no sítio eletrônico da Comissão de Valores Mobiliários (CVM).

Após a coleta, os dados foram trabalhados por meio da planilha eletrônica Excel 2007 e de um software estatístico.

Inicialmente foram analisados os tributos pagos por essas empresas por meio da estatística descritiva. Logo após a análise descritiva o conjunto de dados coletados foi dividido em dois grupos de acordo com a metodologia de Konraht, Schãfer e Ferreira (2014), o primeiro grupo era formado pelas empresas com menor valor adicionado e o segundo com maior valor adicionado. Foi utilizada a mediana para definir esses grupos, os valores iguais ou menores da mediana eram considerados de menor valor adicionado e os valores maiores que a mediana eram considerados como maior valor adicionado.

Com a divisão dos grupos foram calculadas as cargas tributárias médias das empresas por meio de uma adaptação do cálculo de Receita Federal do Brasil obtendo assim a seguinte equação:

$$
C T=\frac{\text { Tributos pagos }}{\text { Valor adicionado }} * 100
$$

Com a divisão dos grupos realizada, procedeu-se a aplicação do teste de médias de Mann-Whitney $U$ com nível de significância de 0,05.

\section{ANÁLISE E DISCUSSÃO DOS DADOS}

O setor de Bens Industriais é composto de 37 empresas distribuídas em cinco subsetores: Comércio; Serviços; Máquinas e equipamentos; Equipamentos elétricos e 
Material de transporte. Foram trabalhados dados referentes a $48,64 \%$ das empresas desse setor e os valores pagos em impostos estão dispostos na tabela 01 a seguir.

Tabela 01- Análise descritiva de empresas do setor de Bens Industriais (Em milhares de reais)

\begin{tabular}{c|c|c|c|c}
\hline Impostos & Mínimo & Máximo & Média & Desvio Padrão \\
\hline 2014 & -161749 & 1213743 & 279728,7 & 415518,96 \\
\hline 2013 & -35617 & 7421447 & 646437,6 & 1729122,86 \\
\hline 2012 & -9677 & 6824468 & 588558,3 & 1585229,90 \\
\hline 2011 & -8536 & 4731904 & 458043,9 & 1091401,37 \\
\hline 2010 & 343 & 4674799 & 442418,9 & 1079274,21 \\
\hline 2009 & -40508 & 4829977 & 395034,3 & 1121472,92 \\
\hline
\end{tabular}

Fonte: Elaborado pelos autores (2015).

Em primeiro lugar deve-se observar a presença de valores negativos referente aos impostos, esses valores são decorrentes de impostos diferidos e prejuízos apurado no período.

O valor médio pago em tributos pelas empresas desse setor nos anos de 2009; 2010; 2011; 2012; 2013 e 2014 são de respectivamente $R \$ 279.728 .700,00 ; R \$ 646.437 .600,00 ; R \$$ 588.558.300,00; $\mathrm{R} \$ 458.043 .900,00 ; \mathrm{R} \$ 442.418 .900,00$ e $\mathrm{R} \$ 395.034 .300,00$. A média geral do setor para os seis anos é igual a $\mathrm{R} \$ 468.370 .287,00$. Conforme a tabela 1 é possível perceber que os valores médios devidos apresentam uma tendência crescente entre os anos de 2009 a 2013, em 2014 esse valor volta a diminuir, por outro lado a amplitude e desvio padrão dos dados se mostram bem maior nesse ano podendo explicar essa diminuição na média dos tributos.

Como o setor anteriormente analisado sofre uma subdivisão, nesse caso em particular em dois subgrupos com o mesmo nome do setor. É composto por 72 empresas, sendo a amostra analisada composta de $43,05 \%$ do total de empresa do setor. A tabela 02 demonstra os impostos pagos por elas.

Tabela 02- Análise descritiva das empresas do setor de construção e transporte (Em milhares de reais).

\begin{tabular}{c|c|c|c|c}
\hline Impostos & Mínimo & Máximo & Média & Desvio Padrão \\
\hline 2014 & 1464 & 1248314 & 221505,8 & 274446,97 \\
\hline 2013 & -1326 & 1289423 & 230037,7 & 259865,56 \\
\hline 2012 & 2255 & 1092581 & 227739,6 & 246123,47 \\
\hline 2011 & 3681 & 974640 & 209178,8 & 209443,24 \\
\hline 2010 & 1951 & 839138 & 179210,8 & 190275,63 \\
\hline 2009 & -183358 & 734107 & 100956,5 & 150990,26 \\
\hline
\end{tabular}

Fonte: Elaborado pelos autores (2015).

O custo médio dos tributos nesse segmento equivale a $\mathrm{R} \$ 221.505 .800,00$ em 2014; $\mathrm{R} \$$ 230.037.700,00 em 2013; R\$ 227.739.600,00 em 2012; R\$ 209.178.800,00 em 2011; R\$ $179.210 .800,00$ em 2010 e R\$ $100.956 .500,00$ em 2009. Nesse setor as empresas demonstraram um crescimento do valor médio pago ao logos dos seis anos analisados. No geral o valor médio pago no período de 2009 a 2014 foi de $\mathrm{R} \$ 194.771 .510,00$.

O maior valor pago foi $\mathrm{R} \$ 1.248 .314 .000,00$ em 2014, ano também com o maior valor médio $\mathrm{R} \$ 221.505 .800,00$ e variação dos dados de $\mathrm{R} \$ 274.446 .970,00$ em volta da média. 0 
menor valor referente a impostos foi de $\mathrm{R} \$-183.358 .000,00$ no ano de 2009 com média de $\mathrm{R} \$ 100.956 .500,00$ e desvio padrão de $\mathrm{R} \$ 150.990 .260,00$.

O próximo setor é o de Consumo Cíclico caracterizado por reunir empresas que dependem de um determinado ciclo econômico para serem consumidas, estão nesse grupo empresas de vestuário, tecidos e calçados, utilidades domésticas entre outros, somam um total de setenta e cinco empresas. Foram analisadas 32\% das empresas desse setor.

Tabela 03- Análise descritiva das empresas do setor de Consumo Cíclico (Em
milhares de reais).
\begin{tabular}{c|c|c|c|c}
\hline Impostos & Mínimo & Máximo & Média & Desvio Padrão \\
\hline 2014 & 2689 & 113413466 & 5060843 & 23082922,61 \\
\hline 2013 & 1836 & 94323366 & 4240868 & 19190712,87 \\
\hline 2012 & -44701 & 89366122 & 4008171 & 18183941,14 \\
\hline 2011 & 4835 & 71744455 & 3269725 & 14588305,58 \\
\hline 2010 & 3228 & 50412494 & 2380550 & 10237432,46 \\
\hline 2009 & 2004 & 68188321 & 3068795 & 13874404,21 \\
\hline
\end{tabular}

Fonte: Elaborado pelos autores (2015).

A estatística descritiva revela que o ano de 2012 foi o único em que foi apresentado valores negativos de impostos nos demais anos todas as empresas apresentaram algum custo relacionado a impostos esses custos em média foram equivalentes a $R \$$ 3.671.491.800,00 nos seis anos de análise.

As empresas do setor não cíclico são aquela que não são afetadas pelos ciclos econômicos o quer dizer que são menos sensíveis a crises econômicas, estão inclusos nessa categoria empresas de bebidas, fumo, saúde entre outras. A tabela 04 a seguir demonstra o custo médio dessas empresas com impostos.

Tabela 04- Análise descritiva das empresas do setor de Consumo não Cíclico (Em milhares de reais).

\begin{tabular}{c|c|c|c|c}
\hline Impostos & Mínimo & Máximo & Média & Desvio Padrão \\
\hline 2014 & -126864 & 17604576 & 2067219 & 4264146,8 \\
\hline 2013 & -115329 & 16990226 & 1891093 & 4026773,85 \\
\hline 2012 & -99767 & 16406328 & 1725891 & 3787736,66 \\
\hline 2011 & -194188 & 14371578 & 1602798 & 3343079,85 \\
\hline 2010 & -137873 & 12766653 & 1450945 & 3034601,054 \\
\hline 2009 & -90718 & 9168551 & 1033839 & 2303239,768 \\
\hline
\end{tabular}

Fonte: Elaborado pelos autores (2015).

O custo médio com impostos pagos por empresas do setor de consumo não cíclico foi

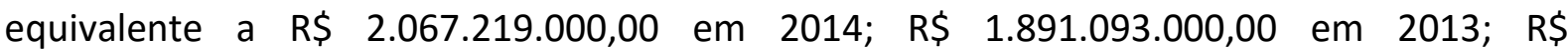
1.725.891.000,00 em 2012; R\$ 1.602.798.000,00 em 2011; R\$1.450.945.000,00 em 2010 e $\mathrm{R} \$$ 1.033.839.000,00 em 2009. Nesse setor também é possível perceber uma tendência crescente nesses custos. A média geral dos seis anos equivale a $\mathrm{R} \$ 1.628 .630 .600,00$.

Do setor Financeiro e outros é composta de intermediários financeiros, securitizadora de recebíveis, empresas de seguros e previdência, além de outros serviços financeiros. Devido a grande a abrangência desse setor ele é um dos maiores da 
BM\&FBovespa, principalmente por causa das empresas do subsetor de fundos tornando a amostra analisada inferior a $10 \%$ do total do setor.

Tabela 05- Análise descritiva das empresas do setor Financeiro e outros (Em milhares de reais).

\begin{tabular}{c|c|c|c|c}
\hline Impostos & Mínimo & Máximo & Média & Desvio Padrão \\
\hline 2014 & 9474 & 2411680 & 422468 & 649514,6 \\
\hline 2013 & 21580 & 2093397 & 387050,5 & 562904,39 \\
\hline 2012 & 15314 & 1859677 & 389450,1 & 538217,42 \\
\hline 2011 & 17285 & 1396161 & 290895,8 & 389815,72 \\
\hline 2010 & 18512 & 5300000 & 598430,4 & 1386453,52 \\
\hline 2009 & 251 & 5896000 & 609660,2 & 1542463,35 \\
\hline
\end{tabular}

Fonte: Elaborado pelos autores (2015).

Os impostos pagos entre 2009 a 2014 correspondem a média de $\mathrm{R} \$ 449.659 .000,00$. O menor valor pago foi em $\mathrm{R} \$ 251.000,00$ em 2009 que também foi o não de maior amplitude nos dados, o maior valor foi $\mathrm{R} \$ 411680000,00 \mathrm{em} \mathrm{2014}$. O ano de 2011 foi o ano que teve a menor amplitude.

O último setor analisado foi o de materiais básicos que contém 41 empresas divididas em seis subsetores que produzem matéria-prima para a indústria, e composto por empresas químicas, siderúrgicas e mineradoras. Os impostos referentes a esse setor estão dispostos a seguir na tabela 06 é representam $50 \%$ das empresas do setor.

Tabela 06- Análise descritiva das empresas do setor de Materiais Básicos (Em milhares de reais).

\begin{tabular}{c|c|c|c|c}
\hline Impostos & Mínimo & Máximo & Média & Desvio Padrão \\
\hline 2014 & -127318 & 2944890 & 531355,7 & 868324,87 \\
\hline 2013 & -194340 & 2605878 & 650119,3 & 904442,36 \\
\hline 2012 & -104676 & 2493143 & 504991,7 & 769333,58 \\
\hline 2011 & -226522 & 2584088 & 492972,6 & 864919,99 \\
\hline 2010 & 25583 & 2252501 & 674585,2 & 857029,89 \\
\hline 2009 & -15021 & 2499422 & 462736,7 & 824044,59 \\
\hline
\end{tabular}

Fonte: Elaborado pelos autores (2015).

A média de impostos pagos no período analisado é de aproximadamente $\mathrm{R} \$$ $552.794 .000,00$. O menor valor dos impostos foi de $\mathrm{R} \$ \mathbf{\$}-226.522 .000,00$ e o maior valor foi de $\mathrm{R} \$ 2.944 .890 .000,00$. A maior variação em torno da média dos valores pagos ocorreu no ano de 2013 R\$ 904.442.360,00 e a menor foi em 2012 R\$ 769.333.580,00.

A tabela 07 apresenta o resultado do teste estatístico de comparação de médias aplicado com as empresas que compõem a amostra visando determinar se existem diferenças no valor da carga tributária suportada por empresas de maior e menor valor adicionado. 
Tabela 07 - Comparação de média dos grupos com maiores e menores valor adicionado

\begin{tabular}{c|c|c|c|c|c|c}
\hline Ano & Bens industriais & $\begin{array}{c}\text { Construção e } \\
\text { transporte }\end{array}$ & $\begin{array}{c}\text { Consumo } \\
\text { cíclico }\end{array}$ & $\begin{array}{c}\text { Financeiros e } \\
\text { outros }\end{array}$ & $\begin{array}{c}\text { Consumo não } \\
\text { cíclico }\end{array}$ & $\begin{array}{c}\text { Materiais } \\
\text { básicos }\end{array}$ \\
\hline $\mathbf{2 0 1 4}$ & 0,063 & 0,027 & 0,005 & 0,07 & 0,069 & 0,001 \\
\hline $\mathbf{2 0 1 3}$ & 0,113 & 0,004 & 0,005 & 0,038 & 0,235 & 0,001 \\
\hline $\mathbf{2 0 1 2}$ & 0,031 & 0,024 & 0,052 & 0,026 & 0,059 & 0,000 \\
\hline $\mathbf{2 0 1 1}$ & 0,05 & 0,000 & 0,006 & 0,017 & 0,013 & 0,000 \\
\hline $\mathbf{2 0 1 0}$ & 0,113 & 0,000 & 0,006 & 0,097 & 0,009 & 0,001 \\
\hline $\mathbf{2 0 0 9}$ & 0,730 & 0,072 & 0,039 & 0,128 & 0,091 & 0,072 \\
\hline
\end{tabular}

Fonte: Elaborado pelos autores (2015).

No setor de bens industriais apenas no ano de 2011 foi possível determinar diferenças estatísticas entre a carga tributária das empresas de maior e menor valor adicionado. $O$ setor de construção e transporte teve a hipótese nula de que os valores das cargas tributárias são iguais entre empresas de menor e maior valor adicionado foi rejeitada nos últimos cinco anos da análise.

Ainda de acordo com a tabela 07 no setor de consumo cíclico apenas para o ano de 2012 não foi possível determinar diferenças estatísticas na média dos grupos, enquanto isso no setor financeiro e outros apenas os anos de 2010 e 2011 apresentaram diferenças nas cargas tributárias.

No setor de consumo não cíclico o teste foi significativo no período de 2011 até 2014 e no último setor a hipótese nula foi rejeitada em cinco dos seis anos analisados, apenas o ano de 2009 não apresentou diferenças na carga tributária de empresas de maior e menor valor adicionado.

Em todos os anos e setores da análise as maiores médias foram das empresas de menor valor adicionado (grupo 01) permitindo assim inferir que para todos os anos onde foram possíveis determinar diferenças estatísticas as empresas com menor valor adicionado apresentam carga tributária superior aquelas maior valor. Esse resultado corrobora com os achados por Konraht, Schãfer e Ferreira (2014) em empresas do setor elétrico. Já Kronbauer et. al( 2009) encontrou diferenças entre as cargas tributárias de empresas como menor valor de ativos, patrimônio líquido e liquidez circulante.

A seguir é apresentado um gráfico demonstrando a evolução dos valores médios pagos ao longo dos seis anos de análise, para uma melhor visualização dos dados procedeuse a deflação dos valores por meio do IGP-M (Índice geral de preços de mercado). A escolha do índice se deu pela variedade dos setores e pela característica do índice em considerar diversos serviços e produtos diferentes em seus cálculos. 


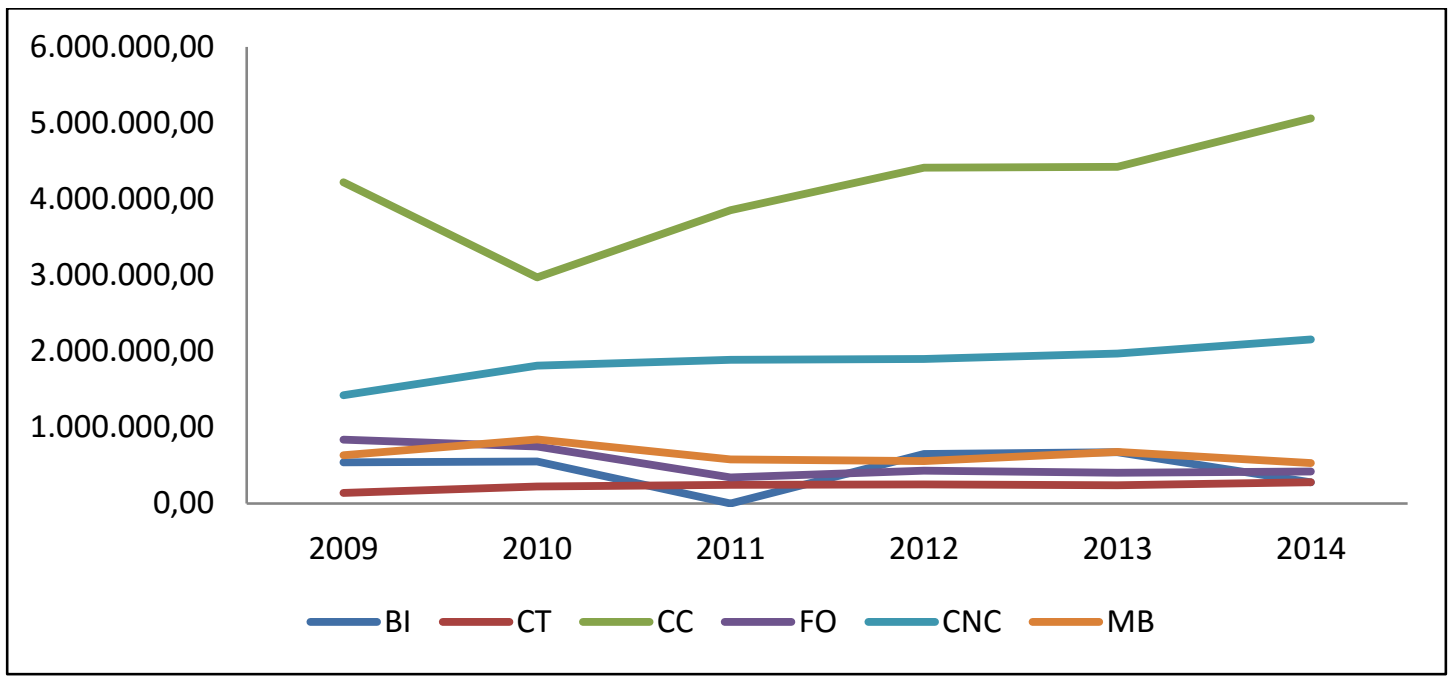

Gráfico 01- Comparação de tributos médios pagos pelas empresas

Fonte: Elaborado pelos autores (2015).

As empresas do setor cíclico foram aquelas que mais pagaram impostos nos seis anos de análise com valores superiores a dois bilhões de reais nos seis anos de análise, seguido das empresas do setor de consumo não cíclico que teve a média de valores pagos superior a um bilhão enquanto as demais empresas apresentaram valores inferiores a esse valor. De acordo com o gráfico, ainda é possível observar que os setores da construção e transporte; consumo não cíclico e consumo cíclico apresentam tendências de crescimento dos custos tributários, enquanto que nas empresas dos setores de bens industriais, financeiros e outros e materiais básicos não foi possível perceber essa tendência.

\section{CONSIDERAÇÕES FINAIS}

O presente trabalho teve por objetivo determinar o custo tributário médio das companhias de capital aberto de seis setores de atividade que negociam ações na Bolsa de Valores, Mercado e Futuro de São Paulo, além de comparar as cargas tributárias das empresas com maior e menor valor agregado.

Por meio da análise executadas foi possível perceber que em média o setor de consumo cíclico foi o que mais pagou impostos nos últimos seis anos totalizando aproximadamente $\mathrm{R} \$ 3.671 .491 .800,00$ em relação aos outros cincos setores. Depois se tem as empresas de consumo não cíclico que totalizam $\mathrm{R} \$ 1.628 .630 .600,00$. Isso implica que as empresas do setor de consumo cíclico e consumo não cíclico demonstraram um maior custo tributário médio.

Já os setores de bens industriais; construção e transporte, Financeiro e outros e materiais básicos possuem um custo médio de respectivamente $\mathrm{R} \$ 468.370 .290,00$; $\mathrm{R} \$$ 194.771.510,00; $\mathrm{R} \$$ 449.659.170,00 e $\mathrm{R} \$ 55.279 .353,00$, isso significa que esses setores alocam menos impostos em seus produtos do que as empresas de consumo cíclico e não cíclico.

Quanto às diferenças existentes entre as empresas como maior e menor valor adicionado observaram-se uma diferença significativa nos últimos quatro anos das empresas dos setores de construção e transporte e materiais básicos, permitido inferir que as empresas de menor valor adicionado apresentaram maior carga tributária nos anos em que o teste estatístico foi significativo. Empresas do setor financeiro e outros apresentaram 
diferenças de médias nos anos de 2011 até 2014. Empresas classificadas no grupo de consumo cíclico não apresentaram diferenças apenas no ano de 2012. O os outros dois setores apenas um ano apresentou diferenças para bens industriais e dois para consumo não cíclico.

Como limitação da pesquisa destaca-se o fato de não terem sido contempladas $100 \%$ das empresas dos setores analisados e a não consideração das especificidades dessas empresas. Como recomendação para pesquisas futuras recomenda-se a análise de outros setores ou o aprofundar o conhecimento dos setores aqui estudados.

\section{REFERÊNCIAS}

BRASIL. Constituição da Republica Federativa do Brasil de 1988. Brasília, 05 de outubro de 1988. Disponível em < http://www.planalto.gov.br/ccivil_03/constituicao/constituicao.htm>. Acessado em fevereiro de 2015.

BRASIL. Lei no 5.172, de 26 de outubro de 1966. Dispõe sobre o Sistema Tributário Nacional e institui normas gerais de direito tributário aplicáveis à União, Estados e Municípios. Brasília, 25 de outubro de 1966. Disponível em: < http://www.planalto.gov.br/ccivil_03/leis/L5172.htm>. Acessado em: Junho de 2015.

BRASIL. LEI № 11.638, DE 28 DE DEZEMBRO DE 2007. Altera e revoga dispositivos da Lei $n^{\circ}$ 6.404, de 15 de dezembro de 1976, e da Lei $n^{\circ} 6.385$, de 7 de dezembro de 1976, e estende às sociedades de grande porte disposições relativas à elaboração e divulgação de demonstrações financeiras. Disponível em: http://www.planalto.gov.br/ccivil_03/_ato20072010/2007/lei/l11638.htm>. Acessado em: 19 de fevereiro de 2015.

CALDEIRA, Luciano Marques. Impacto dos tributos sobre a renda na geração de valor das empresas: Um estudo comparativo internacional. 2006. 168p. Dissertação (Mestrado em Administração) - Universidade de São Paulo, Ribeirão Preto. 2006.

CPC- Comitê de Pronunciamentos Contábeis. ( 2008), Pronunciamento conceitual CPC 09 Demonstração do Valor Adicionado. Disponível em: <http://www.cpc.org.br/CPC/DocumentosEmitidos/Pronunciamentos/Pronunciamento? Id=40>. Acesso em: 18 de fevereiro de 2015.

CUNHA, Jacqueline Veneroso Alves da; RIBEIRO, Maisa De Souza; SANTOS, Ariovaldo Dos. A demonstração do valor adicionado como instrumento de mensuração da distribuição da riqueza. R. Cont. Fin. - USP, São Paulo, n. 37, p. 7 - 23, Jan./Abr. 2005.

CURCINO, Geordana Mendonça; ÁVILA, Lucimar Antônio Cabral De, MALAQUIAS, Rodrigo Fernandes. Percepção dos alunos de ciências contábeis em relação à carga tributária no Brasil: um estudo comparativo entre alunos ingressantes e concluintes. Revista Catarinense da Ciência Contábil - CRCSC - Florianópolis, v. 12, n. 34, p. 66-79, dez./mar. 2013.

EUROPEAN COMMISSIO. A review and evaluation of methodologies to calculate tax compliance costs.Outubro de 2012. Disponível em < 
http://ec.europa.eu/taxation_customs/resources/documents/taxation/gen_info/economic_ analysis/tax_papers/taxation_paper_40.pdf> Acessado em junho de 2015.

FERREIRA, Luiz Felipe; LORANDI, Joisse Antonio; POLUCENO, Ana Carla. Redução do custo tributário em instituições financeiras nacionais por meio da utilização dos juros sobre o capital próprio In: XVIII Congresso Brasileiro de Custos, 2011, Rio de Janeiro - RJ. Anais eletrônicos... Rio de janeiro: 07 a 09 de novembro de 2011. Disponível em: < http://anaiscbc.emnuvens.com.br/anais/article/view/624>. Acessado em: junho de 2015.

GALLO, Mauro Fernando. A relevância da Abordagem Contábil na mensuração da carga tributária das empresas. 2007. 407 p. Tese (Doutorado em Ciências Contábeis ) Universidade de São Paulo. São Paulo 2007.

GIL, Antonio Carlos. Métodos e Técnicas de Pesquisa Social. 6. ed. São Paulo: Atlas, 2012.

KONRAHT, Jonatan Marlon; SCHÄFER, Joice Denise; FERREIRA, Luiz Felipe. A tendência do custo Tributário e o valor adicionado nas empresas de energia elétrica listadas na BM\&FBOVESPA In: XXI Congresso Brasileiro de Custos, 2014, Natal. Anais eletrônico...Natal: Novembro de 2014. Disponível em: < anaiscbc.emnuvens.com.br/anais/article/view/3810>. Acessado em: junho de 2015.

KRONBAUER, Clovis Antonio; OTT, Ernani; SOUZA, Marcos Antonio; COLLET, Cesar José. Evidenciação e análise de carga tributária: Um estudo em empresas brasileiras do setor de energia elétrica. Revista de Contabilidade das Organizações- FEA- RP/USP, v.3, n. 7, p. 3 - 24, set/dez 2009.

MACHADO, Débora Gomes; Azevedo, Teisitel Peres; SILVA, Rogério Piva da. O Impacto Gerado Pela Tributação No Empreendedorismo. ConTexto, Porto Alegre, v. 7, n. 12, 2007.

MACHADO, Márcio André Veras; MACEDO Marcelo Alvaro da Silva; MACHADO Márcia Reis. Análise da Relevância do Conteúdo Informacional da DVA no Mercado Brasileiro de Capitais. R. Cont. Fin. - USP, São Paulo, v. 26, n. 67, p. 57-69, jan./fev./mar./abr. 2015.

MARTINS, Orleans Silva; DANTAS, Ricardo Ferreira. Custo tributário e elisão fiscal: As facetas de um planejamento tributário. Qualit@s Revista Eletrônica, vol.9, n. 3, 2010. Disponível em: <http://revista.uepb.edu.br/index.php/qualitas/article/viewArticle/717>. Acessado em: junho de 2015.

MICHEL, Maria Helena. Metodologia e pesquisa científica em ciências sociais. $2^{a}$ ed. São Paulo: Atlas, 2009.

ORGANIZAÇÃO PARA COOPERAÇÃO E DESENVOLVIMENTO ECONÔMICO- OCDE. Estudos Econômicos da OCDE. Disponível em: http://portal.mte.gov.br/data/files/FF8080812BA5F4B7012BAB3DCFE4122C/Completo_OCD E.pdf $>$. Acessado em: fevereiro de 2015. 
PINHO, Ruy Rabello; NASCIMENTO, Amauri Mascaro. Instituições de Direito Público e Privado: Introdução ao Estudo do Direito e Noções de Ética profissional. 24a Ed. São Paulo: Atlas, 2006.

POHLMANN, Marcelo Coletto; IUDíCIBUS Sérgio De. Relação entre a tributação do lucro e a estrutura de capital das grandes empresas no Brasil. Revista Contabilidade \& Finanças, USP, São Paulo, v. 21, n. 53, maio/agosto 2010.

RECEITA FEDERAL DO BRASIL. Carga tributário no Brasil 2013: Análise por tributos e base de incidência. Dezembro de 2014. Disponível em < http://idg.receita.fazenda.gov.br/dados/receitadata/estudos-e-tributarios-e-

aduaneiros/estudos-e-estatisticas/carga-tributaria-no-brasil/carga-tributaria-2013.pdf >. Acessado em fevereiro de 2015.

RICHARDSON, Roberto Jarry. Pesquisa Social: Métodos e Técnicas, São Paulo: Atlas, 1985.

SILVA, Napoleão Luiz Costa da; TOURINHO, Octávio Augusto Fontes; ALVES, Yann Le Boulluec. O Impacto Da Reforma Tributária Na Economia Brasileira: Uma Análise Com $\mathrm{O}$ Modelo CGE. Instituto de Pesquisa Econômica Aplicada (IPEA). Rio de Janeiro, novembro de 2004.

SIQUEIRA, Rozane Bezerra de; NOGUEIRA, José Ricardo Bezerra; SOUZA, Evaldo Santana de; CARVALHO, Diogo Baerlocher. O custo marginal social da tributação indireta no Brasil: Identificando direções de reforma. Revista de Economia Aplicada, Vol.16, N.3, 2012.

TRIVIÑIOS, Augusto N. S. Introdução a pesquisa em Ciências Sociais: A pesquisa qualitativa em educação, São Paulo: Atlas, 1987. 